\title{
Do estado empreendedor ao mito da não-intervenção: a inovação como instituição nos estados unidos
}

\section{From entrepreneur state to myth of non-intervention: Innovation as an institution in the united states}

Hermes Moreira Jr. ${ }^{1}$

Resumo: Os Estados Unidos consolidaram durante o século XX um ecossistema de inovação responsável por garantir a liderança econômica do ciclo sistêmico do capitalismo mundial. A despeito das reformas nesse ecossistema implantadas durante as desregulamentações neoliberais do governo Reagan, o sistema nacional de inovações norte-americano continua competitivo em virtude da sólida trajetória institucional construída.

Palavras-chave: Sistemas Nacionais de Inovação. Estratégia de Desenvolvimento. Estados Unidos.

Abstract: During the 20th century United States consolidated an ecosystem of innovation responsible for ensuring the economic leadership of world capitalism systemic cycle. Even with neoliberal reforms in this ecosystem that were implemented during the Reagan administration the US national innovation system remains competitive because of the solid institutional trajectory it has built.

Keywords: National Innovation System. Development Strategy. United States.

(cc) EY Direito autoral e licença de uso: Este artigo está licenciado sob uma Licença Creative Commons. Com essa licença você pode compartilhar, adaptar, para qualquer fim, desde que atribua a autoria da obra, forneça um link para a licença, e indicar se foram feitas alterações. 


\section{Introdução}

Joseph Nye, um dos mais destacados defensores das estratégias para a renovação da liderança norte-americana no sistema mundial, afirma que não basta aos rivais do poder americano "a posse de um hardware sofisticado ou de sistemas avançados, e sim a capacidade de integrar um sistema dos sistemas"2. Assim, ele sinaliza que a liderança hegemônica internacional depende de uma trajetória que seja capaz de congregar outras ações para além da competição no nível da produção e consumo. Com efeito, seria necessário ao competidor pela condição líder no atual ciclo hegemônico: 1) centralização de poder para coordenar os rumos da pesquisa e do desenvolvimento tecnológico; 2) alargamentos de mercados com períodos de estimulo à competitividade de maneira acirrada; 3) coordenação de pesquisas setoriais para o avanço na dianteira da condução da trajetória tecnológica; 4) imposição de um padrão tecnológico de consumo à periferia do sistema; 5) projeção do poder global mediante a liderança na competição a nível global;

Nye faz esta observação devido à capacidade que os Estados Unidos tiveram ao longo do século XX de exercer de forma conjugada todas estas condições. Isto significa que é preciso reconhecer que, além de possuir capacidade concreta de ocupar a dianteira dos processos de avanço tecnológico, os principais competidores norte-americanos precisam construir uma trajetória institucional e um modus operandi que torne efetivo o potencial de inovação de suas economias. Ou seja, construir uma trajetória similar àquela estabelecida pelos Estados Unidos, seja no ambiente doméstico ou no plano internacional.

Desde sua etapa de industrialização, até sua consolidação como única potência de alcance global, a economia norte-americana perseguiu alcançar a fronteira mais avançada do sistema econômico-produtivo internacional. Para isto, integrou os lucros derivados de sua produção ao desenvolvimento de novas aplicações científicas e tecnológicas, o que, em grande medida, permitiu que suas empresas pudessem se expandir globalmente. Com este objetivo, constituiu um sistema nacional de inovação altamente moderno e dinâmico, capaz de contemplar as condições indicadas por Joseph Nye para a conquista do posto de principal centro irradiador de inovações da economia global.

Para que ocorra a inovação, sobretudo as "inovações radicais"3, é necessário que sejam criados elementos capazes de interagir na produção, difusão e aplicação do conhecimento gerado e do produto desenvolvido. Para isso funcionar, o chamado ecossistema de inovação, é preciso que todos os atores e instituições que conformam o sistema nacional de inovação atuem de forma convergente com o propósito de ampliar o desempenho inovativo desse ecossistema. Nos Estados Unidos, o ecossistema de inovação funciona a partir do modelo da triple helix, ou hélice tripla, que sintetiza a interação simbiótica entre governo, universidade e indústria ${ }^{4}$. Segundo esta interpretação, a interação se sustenta em torno de três compromissos basilares: proeminente 
papel de universidades, indústrias e governos no sentido de conformação de uma sociedade do conhecimento; um movimento colaborativo em que as três esferas institucionais atuem no sentido de formular uma política de inovação, em detrimento de uma pré-definição governamental; o cumprimento da função institucional tradicional de cada um dos atores somado ao exercício de novos papéis que ampliem o potencial de inovação do sistema constituído.

A interação entre atores e instituições que conformam um ecossistema de inovação capaz de propiciar um ambiente que respalde um sistema nacional de inovação voltado ao avanço científico e tecnológico é resultado de uma complexa amálgama em que o financiamento, a pesquisa e o desenvolvimento, a produção, a comercialização, e, sobretudo, a geração de novos conhecimentos, dependem do direcionamento destes esforços por parte dos agentes inovadores. Nesse sentido, a inovação está longe de constituir um processo estritamente aleatório, mas sim de aprofundados estudos que demonstrem e orientem sua viabilidade.

Nas páginas que seguem, apresentaremos a trajetória institucional da inovação nos Estados Unidos ao longo do século XX. Nosso argumento é o de que para garantir a liderança econômica internacional e a condição hegemônica sistêmica, os Estados Unidos transformaram a inovação em instituição central de sua estratégia de desenvolvimento, e consolidaram um sistema nacional de inovação a despeito das disputas políticas e ideológicas e alternância de perfil de engajamento internacional daqueles que se ocuparam da cadeira mais importante da Casa Branca. Para isso, veremos, inicialmente, como no momento do catching-up norte-americano o Estado participou da estruturação de um sistema nacional de inovações. Na sequência, destacamos a consolidação de uma política de inovação atrelada aos objetivos militares do país durante a Guerra Fria. Por fim, observamos como a "virada" neoliberal da década de 1980 alterou os instrumentos, mas não suprimiu do Estado boa parte da responsabilidade pela sustentação da política de inovação nos Estados Unidos.

\section{O Estado como indutor da trajetória de inovação}

Nos Estados Unidos, ao longo de sua história e trajetória de inovação, o Estado esteve longe de se furtar desta função institucional como parte do sistema nacional de inovação, e ainda contribuiu fortemente para consolidar os outros dois vértices da "hélice tripla", a universidade e a indústria. Ao compreender a formação e o desenvolvimento de setores de alta tecnologia como parte fundamental de sua estratégia, científica, econômica e militar, o Estado se engajou na construção de arranjos institucionais capazes de promover estreita atuação entre governo, indústria e universidade, sem que, desse modo, um planejamento burocrático centralizado viesse a interferir na autonomia necessária ao melhor desempenho do ecossistema de inovação. Block ${ }^{5}$ identificou este formato como próximo ao chamado Estado Desenvolvimentista 
em Rede, ainda que, em virtude de todo o debate interno sobre o papel do Estado e o fundamentalismo de mercado na sociedade norte-americana, esta atuação do Estado tenha sido oculta em muitos momentos.

Cabe, nesse quadro, observar que o Estado Desenvolvimentista em Rede apresenta como fundamento a percepção de uma comunidade de alto nível de expertise científico-tecnológica, demandando forte grau de investimento e educação, sobretudo de nível superior, com foco especial em ciências exatas e engenharias. Ademais, ele deve operar funções de "direcionamento e mobilização de recursos", visando enfrentar importantes desafios tecnológicos e criar novas possibilidades de economia criativa; criar múltiplas possibilidades de ambientes de inovação com a "abertura de janelas" para cientistas, engenheiros, pesquisadores de agências, laboratórios e empresas apresentarem propostas inovadoras e criativas; "realizar intermediação", seja entre as dimensões tecnológicas e comerciais da inovação, buscando ligar uma à outra, por meio de estabelecimento de pontes entre cientistas e homens de negócios, para viabilização da comercialização dos produtos inovadores, seja dentro do processo de inovação e descoberta, aglutinando saberes que estejam desenvolvendo produtos a partir dos mesmos estudos ou com os mesmos fins, para potencializar a capacidade de inovação do sistema; e por fim, operar a "facilitação e adaptação" das inovações ao mercado e ao uso social, tanto por meio de arranjos e arcabouços legais ou institucionais que necessitem ser criados, quanto por meio de indução de novos conceitos culturais ou sociais para o recebimento dos novos produtos 6 .

Ao cumprir estas funções, os Estados Unidos constituíram um sistema nacional de inovações bastante descentralizado, ocorrendo, inclusive, em diversos momentos sobreposição de tarefas por parte de agências e atores institucionais ${ }^{7}$. Tal sobreposição, entretanto, seria benéfica ao objetivo de ofertar o maior número de possibilidades a ideias inovadoras que enfrentassem dificuldades de se viabilizar face à possível excentricidade do projeto. De todo modo, esta "descentralização coordenada" faria parte de um conjunto de princípios norteadores do sistema nacional de inovação norte-americano, juntamente ao foco na "parceria público-privado" para investimentos e financiamento da pesquisa inovadora; com a "partilha cooperativa da expertise" entre a indústria, pesquisadores, laboratórios governamentais e universidades; e a "repartição de ganhos", elemento essencial para garantir o suporte futuro aos mecanismos de inovação ${ }^{8}$.

Com efeito, agências estatais promoveram múltiplas redes de inovação com o intuito de viabilizar que as inovações tecnológicas fossem transformadas em produtos comercializáveis interna e externamente, visando assegurar a vitalidade da indústria doméstica, o nível e a qualidade dos empregos e a primazia econômica global do país. Isto promovendo uma múltipla autonomia ao ecossistema de inovação constituído, ao permitir que o sistema nacional de 
inovação pudesse atuar de forma descentralizada e fragmentada, e sem que houvesse um planejamento burocrático centralizado para o desenvolvimento tecnológico?.

Desse modo, os programas de apoio à pesquisa e desenvolvimento oferecidos pelas agências governamentais, a despeito de não serem as principais financiadoras do sistema nacional de inovação ${ }^{10}$ desempenham papel decisivo na trajetória de inovação dos Estados Unidos e têm constituído uma face importante do capitalismo norte-americano. Sobretudo, ao promover externalidades positivas como um mercado de trabalho associado à produção de novas tecnologias e sua comercialização, bem como estimular a emergência de prestadores de serviços intermediários para a aplicação, acesso e difusão dos novos conhecimentos.

O Vale do Silício, no Estado da Califórnia,_na costa leste dos Estados Unidos, é emblemático para exemplificar o modelo descrito. Com um sistema educacional extremamente qualificado, capitaneado pela Universidade de Stanford e pelo Instituto de Tecnologia da Califórnia (Caltech), a confluência entre os vértices da tripla hélice permitiu um forte investimento governamental em pesquisa básica, a atração de indústrias e de capital de risco para investimentos privados, e o desenvolvimento de um pólo tecnológico que deu origem a inovações que auxiliaram a revolucionar as tecnologias de informação e comunicação. O Ecossistema ali constituído criou um ambiente favorável ao surgimento do principal parque de inovações do mundo, fruto de uma série de políticas, que como veremos, está no seio da tradição e da cultura dos Estados Unidos.

Ainda que os Estados Unidos não tenham, tradicionalmente, formulado um arcabouço de políticas nacionais de inovação ${ }^{11}$ as ações do governo norteamericano alicerçaram a trajetória de desenvolvimento do país desde a fundação de sua república. Este papel decisivo do governo impactou todas as iniciativas que consubstanciaram os Estados Unidos como o principal ecossistema de inovação do mundo.

Posturas adotadas no momento de concepção de instituições e da construção de convenções, normas, rotinas ou procedimentos que se enraízam na estrutura cultural ou organizacional de um determinado agente, tanto na política quanto na economia, exercem efeito de constrangimento que condiciona a trajetória destes agentes e dificulta mudanças subsequentes. Tanto o processo histórico que situa esta construção, quanto o desenvolvimento de ações e caminhos influenciados ou constrangidos por este arcabouço institucional, constituem a chamada trajetória dependente (path dependence). É comum a literatura trabalhar com a perspectiva de que a trajetória dependente gera uma determinada causalidade social ${ }^{12}$. Isso significa que o contexto de fundação e formação de instituições e construções sociais, culturais e políticas exercerá contínua influência no desenvolvimento histórico dessas agências, ao passo que 
mudanças de percurso ou de concepção sobre as regras ou normas que orientam o "jogo" demandam algum grau de influência externa ou a ocorrência de uma "conjuntura crítica" que justifique alternância de rumos ou de posicionamentos.

Obviamente, essa perspectiva oferece um caráter explicativo eminentemente histórico para fotografias do cenário contemporâneo, haja vista que entende que os "resultados anteriores alteram os parâmetros para a evolução posterior" ${ }^{\prime 1}$. Não obstante, além de permitir realizar prescrições, à medida que reconhece a máxima que "a história importa", ou ainda que aquilo que acontece a um sistema hoje pode influenciar profundamente como esse sistema se comportará por um longo período no futuro em virtude dos constrangimentos embutidos na trajetória que se constituirá, auxilia a identificar mecanismos que permitiram a manutenção de regularidades ao longo de um processo de construção histórica. Não por acaso, estudos sobre desenvolvimento econômico recorrem não com baixa frequência a este recurso metodológico-explicativo.

No caso do estabelecimento de um ecossistema de inovação e da configuração dos sistemas nacionais de inovação, é a trajetória dependente que molda os alicerces institucionais responsáveis por conduzir os agentes a determinados comportamentos e reduzir as incertezas acerca da possibilidade de êxito da atividade inovativa. Uma vez que as rotinas de busca, seleção e aprendizado voltados à inovação ocorrem num ambiente dinâmico e diversificado, as instituições possuem importante papel na definição dos padrões de desenvolvimento das trajetórias de inovação. O momento e as condições de fundação das instituições que conformam os sistemas nacionais de inovação devem ser considerados para a avaliação da trajetória dependente, visto que apresentam forte conexão com o contexto presente. Nesse sentido, a mudança técnica e o progresso tecnológico dependem de sucessivos desenvolvimentos dentro desta trajetória que constitui um arcabouço institucional propício à inovação ${ }^{14}$.

Por sua vez, a trajetória dependente viabiliza a mudança técnica e o progresso tecnológico ao passo que tal processo de escolha é comandado por um ciclo de retroalimentação positiva, que eventualmente "trancará" (efetuará o lock-in) o sistema em trajetórias específicas, fazendo com que agentes dotados de diferentes estratégias e expectativas ajustem suas estratégias e expectativas ao ambiente conformado pelo arranjo institucional originado dessa trajetória dependente. De forma mais clara, os agentes serão condicionados a certa irreversibilidade, desde que não haja uma grande interferência externa ou uma conjuntura crítica, se aproveitando de maneira vantajosa dos retornos crescentes do aprendizado acumulado nesta trajetória. Uma vez que a tecnologia tende a não permanecer estática, mas em contínua evolução, a quantidade de informações e o domínio do "fazer" e do "usar" (learning by doing e learning by using) permitem um aprendizado interativo com vistas a melhor performance e desenvolvimento de competitividade tecnológica ${ }^{15}$. 
Ao tomarmos por base a concepção da hélice tripla, verificamos que o arranjo institucional que conformou a trajetória de inovação nos Estados Unidos moldou as ações dos três vértices, governo, universidade e indústria, no sentido de convergirem para cooperação científico-tecnológica ao longo do século XX. Induzidas pela ideia de que os sucessivos desenvolvimentos anteriores continuariam a trazer benefícios futuros, as Agências Governamentais mantiveram e ampliaram o financiamento à pesquisa básica e ao estudo em ciências aplicadas, seja em laboratórios industriais ou nos centros de pesquisas das universidades, com o objetivo de resolver desafios econômicos e sociais que precisassem ser enfrentados; a Universidade permaneceu estimulando seus professores a formar pesquisadores obstinados pela descoberta do novo, trabalhando sempre no limite da fronteira do conhecimento científico; e a Indústria, pressionada pela concorrência e pela necessidade de se sustentar mediante o crescimento do lucro, valorizou o desenvolvimento e aplicação de novas tecnologias buscando inovações que gozassem de valor de mercado.

Ao mesmo tempo, a tendência inercial das instituições dificulta mudanças nas estruturas que conformam esta trajetória. À medida que os mecanismos de retroalimentação dessa tendência se tornam crescentes, a adoção de novos rumos para a trajetória se mostram menos vantajosas ou menos eficientes. São os chamados "custos de transição", quando o risco e a incerteza da mudança se tornam preços muito altos a serem pagos ou desafios muito pouco claros a serem enfrentados ${ }^{16}$.

A trajetória dependente pode, contudo, apresentar situações menos eficientes, e até mesmo contraproducentes. Se o conhecimento e aprendizado acumulados podem ser bastante vantajosos no sentido de reduzir incertezas e oferecer atalhos em virtude de sua adoção anterior pela ação dos agentes, garantindo os retornos crescentes do "caminho auto-reforçante" (self-reinforcing way), como afirma Arthur ${ }^{17}$, a estrutura crescentemente rígida e de difícil alteração tende a repartir o poder de maneira desigual entre os diversos grupos sociais que poderiam participar do arranjo institucional. Sobretudo os grupos de desenvolvimento e constituição mais recente, possuem acesso desproporcional, ou limitado, ao processo de decisão, conferindo assim, a trajetória dependente, castas ou grupos privilegiados dentro de uma trajetória institucional. A ruptura com esta situação só se faz possível a partir de interferência externa ou de uma conjuntura crítica extremamente favorável a estes grupos desguarnecidos das estruturas da trajetória dependente.

A inovação tecnológica teve papel fundamental na constituição de uma trajetória de desenvolvimento econômico nos Estados Unidos, e a hélice tripla, sustentou o eixo da trajetória de inovação do país. O complexo indústria, governo, academia foi elemento central no processo de evolução científico-tecnológica liderado pelos Estados Unidos ao longo do século XX, e a simbiose que ocorreu, com todos os elementos que conduziram a esta 
arquitetura institucional precisam ser compreendidos a fim de se analisar a situação contemporânea.

Para se ter ideia, Friedrich List, um dos pais da economia clássica e principal influência de autores desenvolvimentistas contemporâneos, teve como ponto de inflexão de seu pensamento a emigração para os Estados Unidos por curto um período de sua vida e o contato com a obra de Alexander Hamilton. A defesa que Hamilton fazia da vocação industrial norte-americana, com base em um protecionismo necessário à economia emergente da jovem nação, estimulou a tese do Sistema Nacional de Economia Política de List, segundo a qual a indústria nacional nascente deveria ser respaldada até se encontrar em condições de concorrência com o mercado internacional. Contudo, a despeito de sua construção teórica, List se impressionara com o que havia conhecido nos Estados Unidos: "Quando visitei os Estados Unidos, pus de lado todos os livros, pois a essa altura só tenderiam a desencaminhar-me da via certa. A melhor obra sobre Economia Política que se possa ler naquele país é a vida real" 18

Por todo o debate que precedeu a independência e a fundação da República nos Estados Unidos, seu modelo de intervenção foi muito diverso daquele contido nos "manuais" e também dos implementados nos Estados desenvolvimentistas da América Latina e do Leste Asiático. Por seu turno, o catching-up industrial que ofereceu subsídios para o desenvolvimento econômico do país foi operado com base na busca por novos produtos e ampliação constante da produtividade, sempre com respaldo estatal, conformando aí sua trajetória dependente para os períodos seguintes.

$\mathrm{O}$ alcance da superioridade econômica em relação a seus rivais estrangeiros se deu a partir das últimas décadas do século XIX, quando além da otimização na utilização de insumos, como recursos naturais, investimento em capital e força de trabalho, a inovação tecnológica se tornou fator determinante na trajetória de desenvolvimento do país ${ }^{19}$. E para que a evolução técnica e a mudança tecnológica pudessem exercer papel-chave na trajetória de desenvolvimento, a organização de uma arquitetura institucional voltada aos fundamentos da inovação (pesquisa básica, pesquisa aplicada, desenvolvimento do produto e viabilização comercial) foi estabelecida de forma prioritária no momento de decolagem da economia baseada no conhecimento ${ }^{20}$.

Dois elementos foram cruciais para o fomento da indústria manufatureira nos Estados Unidos, o potencial nacional de exploração de recursos naturais, e o estímulo à imigração de estrangeiros com qualificação e experiência de trabalho industrial no continente europeu ${ }^{21}$. Contudo, foi fundamental a concessão de incentivos e recursos para organização de uma infraestrutura capaz de estimular sua capacidade científica e tecnológica.

O primeiro passo esteve na constituição, e posterior expansão, de um sistema educacional desenhado para desenvolver habilidades e competências 
voltadas à capacidade de alcançar avanço científico-tecnológico. As universidades passaram a serem vistas como importante componente da máquina capitalista, mais ainda devido às significativas vantagens econômicas advindas do investimento em capital humano ${ }^{22}$. A partir de uma lei federal, o governo fez doações de terras por todo o território nacional para a criação de escolas superiores de engenharia e agricultura, os land-grant colleges, o que possibilitou a ampliação do acesso ao ensino superior a todo o interior do país $^{23}$. A massificação da educação superior e a consolidação do ensino universitário nos Estados Unidos permitiu o estabelecimento de um sólido sistema de pesquisa que tornou as universidades centros de excelência e repositório de avançados conhecimentos científicos e tecnológicos públicos essenciais para a mudança técnica e a evolução tecnológica.

Com a expansão do ensino universitário, foi ampliada a oferta de profissionais qualificados e de ideias sobre projetos e produtos inovadores para a indústria. Ao combinar acesso abundante a recursos naturais como carvão, minério de ferro e petróleo, e um grande mercado consumidor, a uma mão-de-obra qualificada e voltada para pensamento e práticas inovadoras, as grandes corporações empresariais norte-americanas introduziram a ideia de apostar em laboratórios de pesquisa e desenvolvimento industrial com vistas à implantação de uma rotina de inovação tecnológica que as colocassem no topo das indústrias manufatureiras a nível internacional. Inovações notadamente ligadas à indústria dos Estados Unidos, como a ferrovia, o automóvel, o avião, a informática e a telemática, a biotecnologia, são fruto desse processo ${ }^{24}$. Ademais, impulsionou mais investimentos públicos em ciência básica e na formação de cientistas e engenheiros responsáveis pelo transbordamento de pesquisas nas áreas de química e eletrônica para outros setores, fortalecendo a parceria entre universidades e grandes empresas por meio das pesquisas acadêmicas e aplicadas realizadas nos grandes laboratórios industriais ${ }^{25}$.

Dessa forma, a liderança norte-americana na produção inovadora e de alta tecnologia ao longo do século XX não foi obra do acaso ou fruto de ações aleatórias e sucesso isolado de empreendedores brilhantes, foi reflexo de maciços investimentos privados e públicos em pesquisa e desenvolvimento e no ensino científico e tecnológico. Ao apostar em campos da ciência básica como a física e a biologia molecular, e das ciências aplicadas, como a metalurgia, a engenharia elétrica e a pecuária, a sociedade norte-americana demonstrou uma forte tendência à inovação, buscando gerar soluções em todos os campos da vida social ${ }^{26}$. Compunha, assim, a estrutura institucional que forjou a trajetória de inovação do país, em que governo, universidade e indústria trabalharam juntos desde a indústria do tecido, do carvão, do ferro, da máquina a vapor, passando pela indústria automobilística, a energia elétrica, a química moderna, até chegar à informática, a biotecnologia e a microeletrônica. 
Este sistema nacional com todas suas especificidades alçou os Estados Unidos à condição de centro hegemônico e dinâmico da economia internacional no início do século XX, seja em função de um protecionismo à indústria nascente, da apropriação do conhecimento produzido no exterior, da qualificação e capacitação técnica da força de trabalho, do estímulo à descoberta e ao avanço da ciência, e da arquitetura de instituições e formulação de políticas voltadas para mudança tecnológica ${ }^{27}$. A aproximação entre governo, empresas e universidades e o fomento público e privado à pesquisa, inclusive àquela voltada às oportunidades comerciais, abriram uma nova porta para o debate sobre modelos de desenvolvimento econômico ao longo do século XX.

A parceria estabelecida, que define a trajetória de desenvolvimento e de inovação dos Estados Unidos, adquire contornos mais evidentes com o passar dos anos a partir da consolidação do sistema de inovação norte-americano baseado na hélice tripla de Etzkowitz. A intensidade dessa relação, com a ampliação dos investimentos governamentais, a ativa participação da indústria e a oferta de cérebros das universidades, consubstanciou o que convencionouse chamar de Science State ${ }^{28}$.

Porém, ao longo do século XX, o governo ampliou sua atuação ao fomentar de maneira bastante sistemática os gastos com pesquisa e desenvolvimento junto a universidades e laboratórios industriais. A principal motivação desse aumento exponencial no financiamento da pesquisa científica foi a obstinação em se estabelecer como detentor da fronteira do conhecimento tecnológico em um cenário internacional que se tornava muito mais competitivo em função das duas guerras mundiais e do início da disputa político-ideológico-militar da Guerra Fria.

\section{O complexo industrial militar acadêmico}

Em meio à disputa político-ideológica que se estabelece com o início da Guerra Fria, os Estados Unidos consolidaram seu padrão de concorrência na competição interestatal a partir do domínio nos diversos ramos da indústria de alta tecnologia, aprofundando o complexo científico-industrial que se estabeleceu durante o esforço de guerra. Nesse sentido, tanto as nações desenvolvidas, quanto as da periferia e semi-periferia do sistema não reuniam condições de competir com a indústria tecnológica norte-americana, que aproveitava o contexto internacional para aprofundar sua superioridade econômica em relação a seus rivais. A posição dos Estados Unidos no cenário internacional estaria, portanto, fundamentalmente ligada à sua capacidade de gerar mudança técnica e inovações tecnológicas em sua indústria manufatureira. Coube ao governo, então, se apropriar deste complexo que conformou o sistema nacional de inovação dos Estados Unidos e destacar um conjunto de agentes públicos que seriam responsáveis por garantir a manutenção dos 
processos de pesquisa e desenvolvimento realizados no país na linha de frente do conhecimento tecnológico disponível.

Isto significou uma inflexão no ecossistema de inovação norteamericano. Ainda que não houvesse mudanças estruturais na composição do sistema de inovação, havia uma nova disposição do governo central em orientar o esforço para a realização de avanços na fronteira do conhecimento. Havia, portanto, uma corrida impulsionada pelo governo federal para que cientistas, engenheiros e laboratórios de pesquisa e desenvolvimento realizassem estudos voltados à solução de problemas e questões tecnológicas específicas. Para tornar essa tarefa viável e com maior nível de excelência, o investimento nacional e o orçamento federal voltados para a pesquisa conheceram uma expansão de grande magnitude.

Ao final da Segunda Guerra Mundial, Vannevar Bush, assessor e consultor do ex-presidente Franklin D. Roosevelt para assuntos tecnológicos, responsável por chefiar o Escritório de Pesquisa e Desenvolvimento Científico dos Estados Unidos, agência governamental que supervisionou os trabalhos do Projeto Manhattan, encaminhou para o presidente norte-americano, Harry Truman, o relatório Science: The Endless Frontier. Nele, Bush fazia defesa da necessidade de que o governo norte-americano entendesse que "o progresso científico é fator essencial para a segurança da nação, para uma melhor qualidade de vida, para a geração de mais empregos e para o progresso cultural dos Estados Unidos" 29 . O relatório recomendava que fosse ampliado o financiamento de fundos públicos para a pesquisa básica, visto que nos últimos anos, sobretudo em virtude do esforço de guerra, os investimentos governamentais e privados em pesquisa científica aplicada nos laboratórios industriais e universidades haviam crescido, bem como a demanda por novas formas de conhecimento científico. Dessa forma, ao investir fortemente na pesquisa básica, o país teria condições de manter o nível de suporte às áreas aplicadas da engenharia que viabilizam a pesquisa militar, bem como fortalecer outras áreas, como a de pesquisas médicas e farmacêuticas, com alto componente de benefício social.

Inspirado pela proposta de Bush, e pressionado pelo conflito que começara a se estabelecer com a União Soviética, em 1950 o governo norteamericano cria a National Science Foundation (NSF), cujo principal objetivo seria financiar, em escala significativa, a pesquisa básica em universidades e centros de pesquisa ${ }^{30}$. Com forte impulso conferido à pesquisa básica, se desdobrariam uma série de descobertas e inovações capazes de serem aplicadas no desenvolvimento de indústrias como a de telecomunicações, eletrônica e computação, químico-farmacêutica, de energia nuclear, e engenharia aeroespacial.

No dispêndio final de investimento em pesquisa e desenvolvimento, o financiamento à pesquisa básica não se compara ao financiamento à pesquisa aplicada, seja por meio do financiamento a laboratórios e institutos de pesquisa, 
ou de compras governamentais. Não obstante, a criação e viabilização de recursos orientados à pesquisa básica via National Science Foundation representou uma mudança na concepção do incentivo à pesquisa nos Estados Unidos, sobretudo ao "empoderar" uma agência governamental que definiria a direção do progresso tecnológico a ser conduzido por cientistas de universidades e laboratórios ${ }^{31}$.

Ao passo que a criação da National Science Foundation de fato estabelece um novo quadro para o financiamento da pesquisa básica nos Estados Unidos, não promove alterações na estrutura do sistema nacional de inovação do país. Ele permanece descentralizado e fundamentado na simbiose entre governo, empresas e universidades. Tomemos como exemplo o National Institutes of Health $(\mathrm{NIH})$, agência voltada para orientar e viabilizar a pesquisa biomédica conduzida pelos institutos e centros de pesquisa vinculados ao Departamento de Saúde nos Estados Unidos, outra fonte de financiamento e orientação à pesquisa básica, e um dos pilares da trajetória de inovação dos Estados Unidos no pós-guerra.

Portanto, o modelo descentralizado de financiamento e suporte à pesquisa nos Estados Unidos se torna mais pulverizado no pós-Guerra, principalmente com o surgimento de novas e pequenas empresas comercializadoras das novas tecnologias, tanto nas áreas de comunicações, eletrônica e computadores, como nas químicas e biomédicas. Formadas a partir de laboratórios de pesquisa de universidades e de grandes empresas, introduzem o fomento do capital de risco privado por meio da participação de agentes do sistema financeiro ${ }^{32}$.

Ocorre que a dinâmica gerada no seio da hélice tripla durante o esforço de guerra, potencializado pela áurea da Guerra Fria e do iminente conflito com os soviéticos, forjou um quadro no qual crescia a importância da indústria militar no conjunto da produção manufatureira norte-americana, e as forças armadas do país demandavam novos sistemas e tecnologias que garantissem sua superioridade diante de qualquer ameaça externa. Diante disso, foi colocada em prática pelo governo federal uma política de financiamento governamental à pesquisa e desenvolvimento sob encomenda de sistemas e componentes a serem adquiridos pelas forças armadas norte-americanas, tornando o Departamento de Defesa o principal financiador de pesquisas em universidades e laboratórios em campos como engenharia de materiais e computação ${ }^{33}$. Ademais, as compras militares beneficiaram um conjunto de empresas que passaram a explorar a produção dual (dual use technology), com a finalidade de desenvolver, produzir e comercializar produtos que tivessem aplicação nos setores militares e civil.

A participação do Departamento de Defesa, do Departamento de Energia, do Departamento de Agricultura, e posteriormente da Comissão de Energia Atômica, somada ao impulso ao National Institutes of Health e à National Science Foundation, proporcionaram um crescimento vertiginoso do financiamento público em pesquisa básica e aplicada nos Estados Unidos 
do pós-guerra, estimulando o desenvolvimento científico-tecnológico de fronteira em praticamente todas as áreas conhecidas: materiais, eletrônica, comunicações, química, farmacêutica, biomédicas, atômica e aeroespacial. Cada uma das agências especializadas recebeu autonomia para adotar medidas que viabilizassem o cumprimento de sua missão, e passaram a estabelecer parcerias com empresas e laboratórios industriais que apresentassem capacidade de alcançar os objetivos esperados, situação que provocou uma espiral constante de inovações no sistema produtivo norte-americano, possibilitando que sua indústria se distanciasse cada vez mais de suas concorrentes estrangeiras em nível tecnológico e capacidade produtiva.

Desse modo, o ecossistema de inovação nos Estados Unidos viveu um boom em que o paradigma científico-tecnológico da inovação passou a depender do conhecimento científico de fronteira. Um paradigma pressionado por grandes exigências ligadas a uma ameaça externa, que demandava pesquisas sofisticadas e dispendiosas, que não conhecia restrições financeiras ${ }^{34}$.

À medida que a Guerra Fria adquiria intensidade, os Estados Unidos passaram a tratar investimentos nas áreas de defesa e ciência \& tecnologia de forma intrínseca, haja vista a compreensão de que seriam setores indissociáveis e estratégicos ao desenvolvimento do país na disputa frente às ameaças externas. O ponto de inflexão que gerou aprofundamento dessa visão, o que posteriormente contribuiu para deturpar todo o sistema nacional de inovação norte-americano, foi o lançamento do Sputnik, satélite soviético que representou o pioneirismo da União Soviética na corrida espacial travada junto aos Estados Unidos. Este evento teve enorme repercussão nos círculos governamentais norte-americanos, que temiam um possível impacto político e ideológico em âmbito global, além do sinal de alerta a respeito da capacidade tecnológica e aeroespacial soviética.

Para superar esta "derrota", visto que os Estados Unidos sempre contaram com sua vantagem na disputa científico-tecnológica frente aos soviéticos, o governo federal tomou algumas medidas para se fortalecer. Dentre elas, destacam-se a reorganização de seu programa espacial, por meio da criação da National Aeronautics Space Administration (NASA) e da Defense Advanced Research Projects Agency (DARPA), ambas em 1958, visando oferecer mais consistência ao desenvolvimento científico-tecnológico e aos projetos de inovação nas áreas aeroespacial e de defesa ${ }^{35}$.

A DARPA, em especial, ofereceu nova vitalidade ao ecossistema de inovação dos Estados Unidos. Funcionou como dínamo da relação entre o governo e as universidades, os laboratórios de pesquisa, grandes e pequenas empresas. Com uma estrutura menos burocrática em relação aos demais programas de financiamento e compras governamentais do Departamento de Defesa, maximizou a competição entre as empresas e auxiliou na facilitação da comercialização de novos produtos, identificou os "becos sem saída" para 
os laboratórios de pesquisa, promoveu o encontro e diálogo entre grupos de cientistas das diferentes universidades, viabilizou novos empreendimentos por meio do contato entre investidores e start-up's. Otimizou o ecossistema de inovação como prevê a figura do Estado Desenvolvimentista em Rede, colocando os agentes do sistema nacional de inovação para trabalhar em alta intensidade e traçando o caminho de retorno da superioridade tecnológica norte-americana por meio do conhecimento de fronteira. Através de sua atuação, o grande projeto do Departamento de Defesa para o desenvolvimento da comunicação via ciência da computação, a ARPANET, que se popularizou com a disponibilização em escala global da Internet, ofereceu a oportunidade aos Estados Unidos de explorarem um novo universo científico-tecnológico e acumularem poder e recursos para garantir a supremacia política e econômica nas décadas seguintes ${ }^{36}$.

Em poucos anos, aproximadamente $90 \%$ dos gastos federais em pesquisa e desenvolvimento eram provenientes do Departamento de Defesa ${ }^{37}$. O governo federal passou a adotar políticas específicas de apoio comercial, no ambiente doméstico e no exterior, a empresas do ramo da indústria militar. O desenvolvimento científico-tecnológico que fora sustentado pelo financiamento do Departamento de Defesa se conformou como "fator-chave da supremacia tecnológica e comercial dos Estados Unidos" e garantiu a "saúde econômica do país", mas não deixara de ser uma preparação para a guerra. E para isso, em escala cada vez mais ampliada, o país orientou seus recursos financeiros e sua capacidade científica e de engenharia industrial, com notável sucesso, para fins militares ${ }^{38}$.

Esta parecia ser uma escalada sem fim, visto que a mobilização era fundamentada na necessidade de posse e manutenção do "armamento superior". Dessa forma, adquirir a superioridade tecnológica para promover inovações no campo militar era considerado uma questão de sobrevivência da nação ${ }^{39}$. Os limites, portanto, não eram financeiros, pois não encontravam restrições orçamentárias. Os limites eram a disponibilidade de conhecimento para ser aplicado em produtos realmente inovadores, que possibilitassem inovações radicais cujo avanço não poderia ser acompanhado pelos rivais.

Este "keynesianismo militar" ${ }^{40}$, que abarcava a provisão de recursos ao processo de pesquisa e desenvolvimento, às compras governamentais, a articulação entre instituições públicas e privadas, influenciou o processo de seleção, difusão e indução das inovações tecnológicas mais modernas na indústria civil norte-americana. Tudo isso sob o compromisso de manter uma superioridade estratégica sobre o adversário. Esse empreendimento orientador recebeu a definição de complexo industrial militar acadêmico. Com intensidade e frequência em ascensão, militares, cientistas, engenheiros, economistas, planificadores, foram todos sendo incorporados ao Complexo Industrial Militar Acadêmico, ampliando sua importância e influência dentro da estrutura política 
norte-americana, e ocupando importante espaço nas agendas de segurança, econômica, política e de inovação tecnológica.

Tanto para proporcionar crescimento econômico internamente, quanto para se defender de movimentos rivais, a capacidade efetiva do complexo industrial militar acadêmico de um Estado é uma das variáveis mais significativas enquanto elemento de poder, principalmente quando se trata de dimensionar seu hard power. Portanto, passou a ser comum a menção a esse complexo como uma das mais influentes engrenagens no processo de formulação da política externa dos Estados Unidos, sobretudo em questões de defesa e segurança nacional, oferecendo suporte à estratégia global norteamericana.

O Presidente Dwight Eisenhower ${ }^{41}$ alertava, em seu discurso de despedida à nação, sobre o peso que este vinha adquirindo a partir da estratégia política da Guerra-Fria: “[...] nas esferas do governo, devemos nos proteger contra a influência injustificada exercida pelo complexo militar-industrial. A possibilidade do surto desastroso de um poder mal orientado existe e permanecerá", e em tom de quase profecia conclui: "não devemos nunca permitir que o peso desta coalizão ameace as nossas liberdades ou os processos democráticos". Nos anos que se seguiram, o complexo industrial militar acadêmico multiplicou sua influência ao oferecer superioridade tecnológica e econômica, fundamentais para a projeção de valores e interesses que sustentariam a posição dos Estados Unidos no sistema internacional.

Por seu turno, a orientação direcionada pelas demandas do Departamento de Defesa pareciam se descolar cada vez mais das necessidades da indústria civil e dos anseios do consumidor comum. O spill over que era promovido pelas inovações da indústria militar para a produção e consumo civil se torna mais complicado à medida que as especificidades tecnológicas da corrida militar se aprofundam ${ }^{42}$. Logo, a "troca de conhecimento" que o complexo industrial militar acadêmico promovia para o sistema nacional de inovação do país perde fôlego, e os Estados Unidos passam a enfrentar os desafios provenientes da conquista de posições nas fronteiras tecnológicas da indústria civil por parte de países aliados, como Japão e Alemanha, com profundo impacto em sua balança comercial nas décadas de 1970 e $1980^{43}$.

Ademais, o ritmo com que a indústria estrangeira gerava inovações voltadas à ampliação da produtividade de sua indústria manufatureira de bens de capital e consumo não era condizente com a necessidade do sistema de inovação norte-americano para promover descobertas ou gerar avanços no conhecimento científico-tecnológico de fronteira. Estava apresentado um dilema para o governo norte-americano: como sustentar a máquina que garantia a "performance que poderia significar a sobrevivência da nação, e reorganizar o ecossistema de inovação para uma nova competição, que não ameaçava a segurança nacional em sentido estrito, mas sim a "saúde econômica" do país?"4 


\section{A reforma neoliberal do ecossistema de inovação nos Estados Unidos}

Ao desgaste político adquirido com a Guerra do Vietnã, à crise fiscal e econômica acentuada com os Choques do Petróleo, e à pressão exercida em função da continuidade do conflito com os soviéticos, se associou um novo elemento de instabilidade aos Estados Unidos, a perda de competitividade industrial em relação a Japão e Alemanha, constituindo um quadro de questionamento sobre a capacidade de manutenção da supremacia norte-americana nas próximas décadas. Nesse sentido, o governo federal decidiu implementar um conjunto de mudanças, com elevado respaldo das elites políticas e sociais do país. $\mathrm{O}$ financiamento à ciência básica continuaria a ser disponibilizado pelo governo, a partir do entendimento de que era peça fundamental para a manutenção do enfrentamento aos soviéticos ${ }^{45}$. Todavia ao invés de fomentar a competitividade industrial norte-americana frente a concorrência estrangeira por meio de uma política industrial centralizada, o governo norte-americano aprofundou a retórica fundamentalista do mercado, deixando a cargo das empresas a escolha de estratégias para conter o desmantelamento do parque industrial civil norte-americano. A perspectiva do governo federal era que o modelo que havia sustentado o sistema nacional de inovação norte-americano nas últimas décadas deveria passar por um rearranjo. A forte ênfase na função governamental de financiar as pesquisas aplicadas deveria ser substituída por um forte engajamento do setor privado, sobretudo do capital de risco e de investidores do mercado financeiro, reposicionando cada um dos vértices que compõem as hélices desse sistema.

Paulatinamente, aquele modelo de confluência entre pesquisa civil e pesquisa militar, que permitiu o desenvolvimento da indústria de comunicações e informática sob forte investimento do Departamento de Defesa e da Agência Espacial Norte-Americana ( $N A S A$ ), foi se esvaziando. O distanciamento dos processos de inovação tecnológica e das necessidades dos setores civil e militar restringiram as possibilidades de spillover das descobertas científicotecnológicas militares para aplicação ao mercado civil. Nesse sentido, os investimentos estatais ficaram cada vez mais restritos ao orçamento do Departamento de Defesa, e voltados à indústria de defesa por meio de financiamento para pesquisa e contratos de compras governamentais, ao passo que os demais setores da economia da inovação buscavam recursos privados para viabilizar suas agendas de pesquisas.

A grande questão que se apresentara a este modelo estava na dificuldade das empresas conseguirem angariar investidores para sustentar a pesquisa e o desenvolvimento de projetos inovadores. Primeiramente, porque o capital de risco, em razão de sua especificidade de busca por retorno rápido e com grau de lucratividade garantido, não tem interesse em financiar pesquisa básica e pesquisa aplicada em fases iniciais ${ }^{46}$. Como decorrência disso, tais empresas deveriam recorrer ao financiamento à pesquisa básica proporcionado 
por agências governamentais, como a National Science Foundation ou o National Institutes of Health, ou desenvolver parcerias com laboratórios de universidades públicas. Em segundo lugar, buscar financiamento privado para as etapas de aplicação e comercialização das pesquisas implicava em uma série de restrições ao patenteamento e aos direitos sobre a propriedade intelectual dessas inovações, em virtude do uso de recursos públicos federais nas fases precedentes, o que acabava desestimulando a participação dos investidores que buscavam grandes lucros com esta parceria.

A saída encontrada pelo governo norte-americano foi incluir questões relativas à inovação e propriedade intelectual como parte da agenda de reformas e desregulamentações colocada em vigor a partir da adoção sistemática do programa neoliberal na década de 1980. Dessa forma, empresas privadas poderiam conduzir pesquisas junto a universidades e laboratórios públicos, e obter benefícios de royalties e licenciamentos sobre produtos frutos dessas pesquisas $^{47}$. Assim, existiria um incentivo para a atração de investimentos privados para a pesquisa e desenvolvimento com vistas à inovação em vista da possibilidade de auferir lucros ao fim do processo a partir da comercialização do produto, mesmo com a presença de recursos federais nas etapas iniciais da pesquisa.

Com este fim, foram sancionadas em 1980 a Stevenson Wydler Technology Innovation Act e a Bayh-Dole Act, regulamentando a transferência de tecnologias geradas em laboratórios públicos e universidades para a indústria, bem como autorizando estas entidades a patentear e comercializar suas inovações, ainda que oriundas de pesquisas financiadas com recursos públicos. Esperava-se com estas leis derrubar velhas barreiras e desconfianças por parte de investidores nas vantagens de financiar pesquisas em laboratórios públicos e universidades, assim como estimular as parcerias público-privadas em laboratórios industriais ${ }^{48}$.

Ainda que o primeiro efeito das novas leis tenha sido a ampliação do depósito de patentes por parte de pesquisadores de universidades e laboratórios públicos, ela não alcançou o objetivo de fazer crescer o número de inovações comercializáveis conforme a necessidade de retomar a capacidade competitiva do país. O capital privado, em meio ao ambiente de crise e incerteza que se constituía na economia norte-americana, como reflexo do cenário internacional, ainda não estava disposto a assumir o seu papel de fomento à pesquisa. Por isso, foi apresentado pelo governo Reagan, em 1982, o Small Business Innovation Research (SBIR), programa que instituía um "sistema público de capital de risco", voltado ao financiamento de pesquisa inovadora, para pequenas empresas ${ }^{49}$. Seu propósito era o de estimular pequenas empresas a realizarem atividades de pesquisa inovadora, sobretudo de alto risco, buscando o desenvolvimento de novos produtos e novos processos com injeção de recursos públicos oriundos não apenas da National Science Foundation e do National 
Institutes of Health, mas também do Departamento de Defesa, Departamento de Energia, Departamento de Educação, Departamento de Comércio, Departamento de Transportes, Departamento de Agricultura, Agência de Proteção Ambiental e NASA. Dessa forma, o programa atrairia capital privado para empresas com o intuito do desenvolvimento do negócio, ao passo que o desenvolvimento do produto estaria garantido pelo aporte estatal. O SBIR se estrutura a partir de incentivos governamentais obrigatórios e estabelecidos em lei que garantem o fomento a projetos de pesquisa em inovação e difusão de produtos de conteúdo tecnológico

Isso implicaria um maior número de novas pequenas empresas de conteúdo tecnológico participando da cadeia de fornecedores das agências governamentais e estimulando o desenvolvimento científico-tecnológico no sistema produtivo norte-americano. O programa estabelecia participação governamental nas duas primeiras fases do desenvolvimento do produto (viabilidade e pesquisa, e desenvolvimento), e atuação do investimento privado na terceira fase, de aplicação e introdução da nova tecnologia no mercado. As agências possuem autonomia para selecionar as propostas apoiadas, seguindo critérios estabelecidos pelo Programa SBIR e mecanismos de certificação de projetos e avaliação de resultados. Este programa permanece em vigor até os dias de hoje ${ }^{50}$.

Ao longo da década de 1980 outras legislações vieram a dar suporte e aperfeiçoar as novas regulamentações estabelecidas pela lei de inovações, como a National Cooperative Research Act e a Patent and Trademark Clarification Act, ambas em 1984, a Federal Technology Transfer Act, em 1986, a Omnibus Trade and Competitiveness Act, de 1988, e a National Competitiveness Technology Transfer Act, no ano de 1989, todas estabelecendo critérios voltados à cooperação entre governo e empresas para a pesquisa, produção, comercialização e transferência de tecnologia ${ }^{51}$. Este novo marco regulatório estabelecido proporcionou a pesquisa conjunta entre universidades, laboratórios governamentais e empresas, com a redução de riscos ao investidor privado, uma vez que as fases críticas de incerteza para o desenvolvimento do produto, o chamado "vale da morte" da inovação, seriam realizadas com financiamento público $^{52}$. O Estado, portanto, atuaria no sentido de corrigir falhas do mercado e diminuir a assimetria de informações, auxiliando a viabilizar a comercialização das inovações.

Apesar do forte contexto de redução da intervenção estatal na economia, e da desregulamentação de diversos instrumentos que garantiam o monopólio do Estado sobre os resultados de pesquisas realizados com financiamento político, conforme defendia o pensamento neoliberal, Freeman ${ }^{53}$ afirma que, "o papel do governo federal na promoção da inovação está longe da posição passiva e não-intervencionista". Todavia, o conjunto de novas regulamentações e legislações permitiu a formação de um número maior de parcerias público- 
privadas e a composição de joint ventures focadas em desenvolvimento científico-tecnológico. Ao reduzir as incertezas do mercado no período crítico da pesquisa e desenvolvimento de novos produtos, o Estado conseguiu engajar mais empresas no financiamento à inovação de produtos com potencial de mercado.

No médio prazo, o capital privado tornou-se o principal provedor de recursos para o ecossistema de inovação norte-americano, e seu sistema nacional de inovações gerou novas tecnologias voltadas às áreas de defesa, saúde e comunicações. Não obstante, o Estado deixou de exercer controle sobre o retorno dos fundos investimentos em pesquisa básica e aplicada, ficando a cargo das próprias empresas e laboratórios de pesquisa a decisão e alocação de reinvestimento para novos ciclos de inovação. Desse modo, o Estado passou a assumir os riscos de investimentos em tecnologias radicais e consideradas estratégicas, se tornou o principal comprador por meio de contratos públicos de compras governamentais, ofereceu incentivos e subvenções, além de financiamento direto, mas deixou a cargo do mercado a possibilidade de lucrar com os negócios viáveis ${ }^{54}$.

A relação simbiótica entre os vértices da hélice tripla, que configurou o sistema nacional de inovação nos Estados Unidos, foi cedendo espaço a uma relação parasitária ${ }^{55}$. Em meio à necessidade de retomada da competitividade da indústria norte-americana, o financiamento público e a pesquisa universitária passaram a estar a serviço do setor empresarial. Contata-se uma socialização de riscos e incertezas, por meio do financiamento público e suporte da pesquisa universitária, enquanto a obtenção dos retornos financeiros e do lucro se dá por meio de apropriação privada, das empresas e investidores privados de capital de risco.

Mesmo diante dessa situação de fragilidade apresentada pelo ecossistema de inovação do país no âmbito das reformas neoliberais, François Chesnais e Catherine Sauviat identificam diversos fatores que sustentam a pujança do sistema nacional de inovações nos Estados Unidos a despeito do quadro internacional mais competitivo que se configurou nas últimas três décadas ${ }^{56}$. Dentre eles se destacam o aprendizado e conhecimento acumulado, oligopólios setoriais e monopólios tecnológicos, bem como uma alta qualificação educacional e profissional sustentadas por um sistema universitário altamente desenvolvido. O que reforça a importância da trajetória dependente para a manutenção do nível de desenvolvimento econômico do país.

\section{Considerações Finais}

Os Estados Unidos consolidaram seu sistema nacional de inovação a partir da primeira metade do século XX com forte engajamento estatal. Os vínculos estabelecidos entre agências governamentais, universidades e empresas geraram um ecossistema que permitiu à economia do país conhecer 
um alto grau de dinamismo e liderar todo o processo de desenvolvimento econômico no atual ciclo do capitalismo. Com o desenrolar da Guerra Fria e o aprofundamento das disputas entre soviéticos e norte-americanos, a fronteira tecnológica ganhou nova dimensão, não apenas com a responsabilidade de conduzir a estrutura produtiva econômica, mas também de garantir a manutenção da segurança nacional.

À luz das transformações econômicas, políticas e sociais das décadas de 1970 e 1980, um conjunto de mudanças no modelo de financiamento da inovação foi colocado em prática, com reformas e legislações voltadas a fortalecer a perspectiva do financiamento privado. Foram regulamentações "desregulamentadoras", transferindo recursos públicos para viabilizar retornos a entes privados, dentro de um quadro mais amplo de desregulamentações no setor público e redução da atuação do Estado na economia, bem como de aprofundamento das inovações financeiras ${ }^{57}$. Logo, se aprofundou a dependência do financiamento privado via capital de risco, que buscou se alocar nos setores em que a possibilidade de retorno seria mais factível e a concorrência menos severa, apenas instrumentalizando o recurso estatal para sua viabilização.

Esse novo modelo, que se configurou ao longo das últimas três décadas, com um ambiente regulatório favorável à parceria entre financiamento público e capital privado, no qual havia garantia de direitos de patenteamento e propriedade privada a investidores financeiros em detrimento do Estado, impactou diretamente setores vinculados à inovação radical, ou seja, aquela que corresponde à introdução na economia de uma tecnologia mestra ou genérica capaz de afetar a organização do trabalho e a produtividade em um grande número de atividades. Além do imperativo de busca por retornos de curto prazo, ao passo que inovações radicais exigem tempo e paciência até a apresentação de resultados satisfatórios e comercializáveis, grande parte dos investidores privados prefere participar do financiamento de inovações de baixo risco ou de mercados consumidores com demanda já estabelecida. O modelo fragilizou o ecossistema de inovação e a capacidade de competitividade da economia norteamericana frente à nova conjuntura da economia política internacional, tendo sua condição de principal propulsora de inovações, ao menos incrementais, garantida pela estrutura institucional construída ao longo de sua trajetória de inovação no século XX.

\section{Notas}

1 Doutor em Relações Internacionais pela UNESP. Professor da Universidade Federal da Grande Dourados. e-mail: hermesmoreira@ufgd.edu.br

2 NYE Jr., Joseph. O Paradoxo do Poder Americano: Por Que a Única Superpotência do Mundo Não Pode Prosseguir Isolada. São Paulo: Editora UNESP, 2002, p. 119. 
3 IZERROUGENE, Bouzid. Inovação Tecnológica e Cíclo Econômico. Revista da Sociedade Brasileira de Economia Política, Uberlândia, v. 35, p. 71-90, 2013.

4 ETZKOWITZ H. The Triple Helix: Industry, University, and Government in Innovation. Nova York: Routledge, 2008.

5 BLOCK, Fred. Swimming Against the Current: the Rise of a Hidden Developmental State in the United States. Politics \& Society, New York, v. 36, n. 2, p. 169-206, jun 2008.

6 BLOCK, Fred. The Invisible Hand of Government. In: BLOCK, Fred; KELLER, Matthew. State of Innovation: the U.S. government's role in Techonology Development. Boulder: Paradigm Publishers, 2011.

7 COSTA, Karen F. A política de incentivo à Inovação dos Estados Unidos: arcabouço institucional, atores e processos. Trabalho Apresentado no $36^{\circ}$ Encontro Anual da ANPOCS, 2012.

8 BLOCK, op. cit. pp. 31-34.

9 LUZ, Rafael R. A revolução a partir do átomo: o papel do Estado no desenvolvimento do setor de nanotecnologia nos EUA. Dissertação de Mestrado. Instituto de Relações Internacionais. Universidade de Brasília, 2014.

10 COSTA, Karen F. Inovação e Desenvolvimento nos Estados Unidos: Os Anos Obama. Trabalho Apresentado no $4^{\circ}$ Encontro Nacional da Associação Brasileira de Relações Internacionais, 2013.

11 ALIC, John; MOWERY, David; RUBIN, Edward. U.S. Technology and Innovation Policies: lessons for Climate Change. Pew Center On Global Climate Change. Arlington: Texas, 2003.

12 HALL, Peter. A.; TAYLOR, Rosemary C. R. Political science and the three new institutionalisms. Political Studies, New Jersey, v. 44, n.4, p.936-957, 1996.

13 SKOCPOL, Theda. Social Policy in the United States: Future. Possibilities in Historical Perspective. Princeton, NJ: Princeton. University Press, 1995. p. 106.

14 NELSON, Richard. Recent evolutionary theorizing about economic change. Journal of Economic Literature, New York, n. 33, p. 48-90, 1995.

15 ARTHUR, W. Brian. Competing technologies, increasing returns and lock-in by historical events. The Economic Journal, Massachusetts, v. 99, n. 394, p. 116-131, 1989.

16 PIERSON, Paul. Increasing returns, path dependence, and the study of politics. American Political Science Review, Washington, v. 94, n. 2, p. 251-267, 2000.

17 ARTHUR, op. cit.

18 LIST, Georg Friedrich. Sistema Nacional de Economia Politica. São Paulo: Nova Cultural, 1986. p. 05.

19 ROSENBERG, Nathan. Por dentro da caixa-preta: tecnologia e economia. Campinas: Editora Unicamp, 2006.

20 BINGHAM, Richard D. Industrial Policy American Style: from Hamilton to HDTV. New York: M.E. Sharpe, 1998.

21 CHANG, Ha Joon Chutando a Escada: a estratégia do desenvolvimento em perspectiva histórica. São Paulo: Editora UNESP, 2003. 
22 NELSON, Richard. As Fontes do Crescimento Econômico. Campinas: Editora Unicamp, 2006.

23 MORAES, Reginaldo C. C. Ensino superior de curta duração: a experiência norteamericana dos Community Colleges. Cadernos de Pesquisa, Fundação Carlos Chagas, Rio de Janeiro, v. 44, p. 450-467, 2014.

24 MORAES, Reginaldo C. C. Paradoxos do ensino superior norte-americano: uma nota de pesquisa. Educação \& Sociedade, Campinas, v. 34, p. 25-45, 2013.

25 ROSENBERG, op. cit.

26 VIEIRA, Pedro A.; FERREIRA, Luiz M. O Brasil na atual conjuntura científico-tecnológica da economia mundo capitalista. In: VIEIRA, Rosângela: O Brasil, a China e os Estados Unidos na atual conjuntura da economia-mundo capitalista. Marília: Oficina Universitária, 2013.

27 MOWERY, David; ROSENBERG, Nathan. Trajetórias da inovação: a mudança tecnológica nos Estados Unidos da América no século XX. Campinas: Editora Unicamp, 2005.

28 BLOCK, Fred; KELLER, Matthew. State of Innovation: The U.S. Government's Role in Technology Development. Boulder: Paradigm Publishers, 2011.

29 BUSH, Vannevar. Science: The Endless Frontier. New York: American Council of Learned Societies, 1945.

30 WESSNER, C. (ed.). The Small Business Innovation Research Program: Challenges and Opportunities. Washington D.C.: National Academy Press, 1999.

31 ALIC, John. Trillions for Military Technology: How the Pentagon Innovates and Why it costs so much. New York: Palgrave Macmillan, 2007.

32 MOWERY; ROSENBERG, op. cit.

33 NELSON, op. cit.

34 MEDEIROS, Carlos A. O Desenvolvimento Tecnológico Americano no Pós-Guerra como um Empreendimento Militar. In: FIORI, José L. O Poder Americano. Petrópolis: Vozes, 2004.

35 MAZZUCATO, Mariana. O Estado Empreendedor. Desmascarando o mito do setor público vs. setor privado. São Paulo: Portfólio-Penguin, 2014.

36 Idem.

37 MOWERY; ROSENBERG, op. cit.

38 MEDEIROS, op. cit.

39 GILPIN, Robert. War and Change in World Politics. Nova York: Cambridge University Press, 1981.

40 ANDERSON, Perry. Balanço do neoliberalismo. In: SADER, Emir; GENTILI, Pablo. Pós-neoliberalismo: as políticas sociais e o Estado democrático. Rio de Janeiro: Paz e Terra, 1995.

41 EISENHOWER, Dwight. Military-Industrial Complex Speech. The White House. United States Capitol, Washington, D.C., 1961.

42 DIAMOND, David. Defence Innovation: Internal and External Factors. RUSI Defence Systems. Spring, 2006. 
43 BRENNER, Robert. The Economics of Global Turbulence: The Advanced Capitalist Economies from Long Boom to Long Downturn, 1945-2005. New York: Verso, 2006.

44 ALIC, John A.; BRANSCOMB, Lewis; BROOKS, Harvey; CARTER, Ashton B.; EPSTEIN, Gerald L. Beyond Spinoff: Military and Commercial Technologies in a Changing World. Boston: Harvard Business School, 1992. p. 09.

45 STOKES, Donald E. O quadrante de Pasteur: a ciência básica e a inovação tecnológica. Campinas - SP: Editora da Unicamp, 2005.

46 SMITH, Keith. Medidas políticas para apoiar inovação: experiências internacionais. In: CGEE. Avaliação de políticas de ciência, tecnologia e inovação: diálogo entre experiências internacionais e brasileiras. Brasília: Centro de Gestão e Estudos Estratégicos, 2008.

47 MARZANO, Fábio. Políticas de inovação no Brasil e nos Estados Unidos: a busca da competitividade - oportunidades para a ação diplomática. Brasília: Funag, 2011.

48 ETZKOWITZ, op. cit.

49 BLOCK, op. cit.

50 MATOS, Paulo Todescan; ABDAL, Alexandre. Estados Unidos: mudanças jurídico-institucionais e inovação. ARBIX, G. (org.). Inovação: estratégia de sete países. Brasília, DF: ABDI, 2010.

51 LEYDEN, Dennis P.; LINK, Albert N. Public Sector Entrepreneurship: US Technology and Innovation Policy. New York: Oxford University Press, 2015.

52 MAZZUCATO, op. cit.

53 FREEMAN, Chris. Um pouso forçado para a "nova economia"? A tecnologia da informação e o sistema nacional de inovação dos Estados Unidos. In: LASTRES, Helena; CASSIOLATO, José E. e ARROIO, Ana M. Conhecimento, sistemas de inovação e desenvolvimento. Rio de Janeiro: Contraponto, 2005. p. 64.

54 PEREZ, Carlota. Prefácio: desvendando mitos. In: MAZZUCATO, Mariana. O Estado Empreendedor. Desmascarando o mito do setor público vs. setor privado. São Paulo: Portfólio-Penguin, 2014.

55 MAZZUCATO, ibidem.

56 CHESNAIS, François; SAUVIAT, Catherine. O financiamento da inovação no regime global de acumulação dominado pelo capital financeiro. In: LASTRES, Helena; CASSIOLATO, José E. e ARROIO, Ana M. Conhecimento, Sistemas de Inovação e Desenvolvimento. Rio de Janeiro: Contraponto, 2005.

57 STIGLITZ, Joseph. Os Exuberantes anos 90: uma nova interpretação da década mais próspera da história. São Paulo: Companhia das Letras, 2003.

Recebido em 17/05/2017

Aprovado em 03/11/2017 